\title{
THE EPIDEMIOLOGY OF HUMAN TRICHINELLOSIS IN ChINA dURING 1964-1999
}

\author{
WANG Z.Q.* \& CUI J.*
}

\section{Summary :}

The large foci of trichinellosis are mainly located in the southeastern, the central and northeastern China. By the end of 1999, human cases with trichinellosis have been recorded in 17 out of 34 Provinces/Autonomous Regions/Municipals (P/A/M) of China. The seroepidemiological surveys of $T$. spiralis infection in humans were carried out in nine out of $34 \mathrm{P} / \mathrm{A} / \mathrm{M}$. The overall seroprevalence was $5.3 \%$. The prevalence detected by muscle biopsy in Henan province was $2.5 \%$. From 1964 to 1999 , 548 outbreaks of trichinellosis, with 23,004 cases and 236 deaths, were recorded in $12 \mathrm{P} / \mathrm{A} / \mathrm{M}$ of China. Pork is the predominant source of outbreaks of human trichinellosis in China, $525(95.8 \%)$ out of 548 outbreaks were caused by eating pork. However, 14 outbreaks resulting from the consumption of mutton and game meat occurred in recent years, suggesting the increasing significance of herbivorous and wild animals as source for human trichinellosis.

KEY WORDS : trichinellosis, epidemiology, prevalence, outbreak, herbivores, wildlife, China.

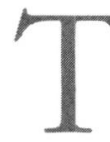
richinellosis is a serious parasitic zoonosis with a worldwide distribution. In China, Trichinella spiralis larvae were found in swine muscle in Xiamen city of Fujian province for the fist time over a century ago. Fifty years later, T. spiralis larvae were demonstrated in dogs, cats and bears in the Northeast of China and in rats in Fujian province. But, the human infection with $T$. spiralis were not recorded in China before 1964, when the first case with trichinellosis occurred in Xizang (Tibet) (Huang, 1965). Since then, many sporadic cases and outbreaks of trichinellosis have been reported and the incidence of this disease has been increasing and the endemic areas have been expended with the changes of consumption of Chinese inhabitants. It has become an important public health problem in China. Over the past decades, many works on the epidemiology of trichinellosis have been carried out by Chinese scientists. Unfortunately, the majority of the papers have been published in the Chinese language. In addition, the reliable nationwide data

* Department of Parasitology, Henan Medical University, Zhengzhou 450052, China.

Tel.: (86 ) 371-6975190 - e-mail: wangzhongq@371.net about the incidence of trichinellosis in humans were rare in China. Therefore, we review the epidemiology of human trichinellosis in China from 1964 to 1999.

\section{EPIDEMIOLOGICAL DATA}

\section{SEROPREVALENCE OF HUMAN TRICHINELLOSIS}

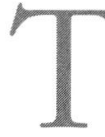
he seroepidemiologic surveys of $T$. spiralis infection in humans were carried out in nine out of 34 Provinces/Autonomous Regions/ Municipals (P/A/M) of China during 1991-1998 (Table I). Specific anti-Trichinella antibodies (IgG) were determined by indirect ELISA using the soluble muscle larva antigen of $T$. spiralis ( $\mathrm{Li}$ et al., 1991). The mean O.D. value of negative sera from 184 healthy persons was 0.16 . The positive cutoff was determined to be four times of the mean of negative sera. The overall seroprevalence was $5.3 \%$. The higher seroprevalence was mainly located in Southwestern and Central China. Seroprevalence tended to increase with age, but did not differ significantly between males and females and among different professional individuals.

\section{PREVALENCE OF HUMAN TRICHINELLOSIS}

The serological tests might overestimate the prevalence of Trichinella infection in humans because of the false positivity or cross reaction with other helminths. In order to know the true prevalence, samples of striated muscle from surgery patients (with other disease other than trichinellosis) were randomly collected during operation for the examination of $T$. spiralis larvae by microscopy in Henan province during 1982-1996. The resulted showed that the overall prevalence of human infection with T. spiralis was $2.5 \%$ (Table II).

\section{OUTBREAKS OF HUMAN TRICHINELLOSIS}

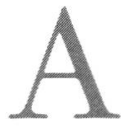

$n$ outbreak of trichinellosis in China was first reported in Yunnan province in March of 1964 (Bai, 1965). But in fact, the first out- 


\begin{tabular}{|c|c|c|c|c|c|}
\hline $\mathbf{P} / \mathbf{A}$ & Year & No. examined & No. positive & Rate positive (\%) & Reference \\
\hline Xizang & 1991 & 1080 & 262 & 24.3 & Gou et al., 1991 \\
\hline Yunnan & 1991 & 3842 & 519 & 13.5 & Yang, 1991 \\
\hline Guangxi & 1995 & 175 & 56 & 32.0 & Gan et al., 1995 \\
\hline Sichuan & 1993 & 502 & 4 & 0.8 & Wang, 1993 \\
\hline Jiangsu & 1997 & 410 & 5 & 1.2 & Ma et al., 1997 \\
\hline Hube & 1998 & 4719 & 574 & 12.2 & Ye et al., 1998 \\
\hline Henan & 1999 & 2441 & 120 & 4.9 & Cui et al., 1999 \\
\hline Hebei & 1994 & 6204 & 41 & 0.7 & Liu et al., 1994 \\
\hline Lioning & 1992 & 6842 & 77 & 1.1 & Xiu et al., 1992 \\
\hline Ningxia & 1991 & 7810 & 132 & 1.7 & Fu et al., 1991 \\
\hline Total & & 34025 & 1790 & 5.3 & \\
\hline
\end{tabular}

Table I. - Seroprevalence of human infection with Trichinella spiralis in China.

\begin{tabular}{|c|c|c|c|c|c|}
\hline Areas & Year & No. examined & No. infected & $\%$ infected & Reference \\
\hline Xizang & 1991 & 1080 & 262 & 24.3 & Gou et al., 1991 \\
\hline \multirow[t]{3}{*}{ Nanyang } & 1982 & 176 & 3 & 1.7 & Gong (pers comm.), 1982 \\
\hline & 1986 & 587 & 15 & 2.6 & Wu et al., 1986 \\
\hline & 1991 & 172 & 7 & 4.1 & Chang et al., 1991 \\
\hline Luohe & 1996 & 113 & 1 & 0.9 & Li et al., 1996 \\
\hline Total & & 1048 & 26 & 2.5 & \\
\hline
\end{tabular}

Table II. - Prevalence of human infection with T. spiralis detected by biopsy in Henan.

break in China occurred in the same province in November 26, 1960, with 78 human cases (Zheng L.Z., personal communication). According to the retrospective epidemiological study, 10 outbreaks with 276 cases and 12 deaths occurred only in Yunnan during 1960-1963 (Pang et al., 1999). The epidemic foci of human trichinellosis were mainly located in Southwestern China during the 1960s and 1970 s, but from the beginning of 1980s, another two large endemic areas of trichinellosis have been found in Central and Northeastern China. From 1964 to 1999, 548 outbreaks of human trichinellosis, with 23,004 cases and 236 deaths, were recorded in $12 \mathrm{P} / \mathrm{A} / \mathrm{M}$ of China (Table III).

\section{SPORADIC CASES WITH TRICHINELLOSIS}

$\mathrm{D}$ uring 1964-1999, 3,540 sporadic cases with trichinellosis were recorded in China, most of them occurred in the above-mentioned endemic areas where the outbreaks have occurred, especially in Hubei (1641 cases), Hennan (846 cases), Yunnan (668 cases), Lioning (380 cases) and Guangxi (41 cases). Moreover, sporadic cases were also recorded in Shanghai, Guangdong, Jiangxi, Shandong and Hebei. Hence, human cases with trichinellosis have occurred in 17 out of $34 \mathrm{P} / \mathrm{A} / \mathrm{M}$ of China. Following the development of tourism in China in recent years, tourists from non-endemic areas also developed

\begin{tabular}{lrrrll}
\hline \multicolumn{1}{c}{ P/A/M } & No. outbreaks & No. cases & No. deaths & Source & Reference \\
\hline Yunnan & 442 & 20344 & 217 & Pork, wild boar, mutton, bamboo rat, muntjak & Pang et al., 1999 \\
Xizang & 8 & 155 & 8 & Pork & Zou, 1982 \\
Gongxi & 3 & 93 & 6 & Pork & Lu, et al., 1996 \\
Sichuan & 2 & 67 & 1 & Bear, pork & Wang \& Lu, 1981 \\
Hubei & 65 & 1548 & 0 & Pork & Wu et al., 1996 \\
Henan & 14 & 514 & 0 & Pork, mutton, beef & Wang, et al., 1997 \\
Lioning & 4 & 33 & 0 & Pork, mutton, dog & Pang, 1991 \\
Jilin & 5 & 71 & 0 & Dog, mutton & Jiang et al., 1989 \\
Heilongjiang & 2 & 164 & 0 & Mutton & Xu \& Mu, 1981 \\
Shanxi & 1 & 5 & 0 & Pork & HaO et al., 1997 \\
Beijing & 1 & 6 & 0 & Dog & Wang et al., 1989 \\
Hongkong & 1 & 4 & 4 & Pork & Pun et al., 1983 \\
\hline Total & 548 & 23004 & 236 & & \\
\hline
\end{tabular}

Table III. - Outbreaks of human trichinellosis in China during 1964-1999. 
trichinellosis. Over the period from 1995 to 1998, 11 cases of travel-associated trichinellosis were diagnosed only in our department.

\section{SOURCE OF INFECTION}

$\mathrm{P}$ ork is the predominant source of infection of outbreaks of human trichinellosis in China. Out of 548 outbreaks, 525 (95.8\%) outbreaks were caused by eating pork. However, 8 (1.5\%) outbreaks caused by eating dog meat, seven (1.3\%) outbreaks by eating mutton, seven (1.3\%) outbreaks by eating game meat and one $(0.2 \%)$ by eating beef. Outbreaks that occurred in Southwestern China are commonly associated with ethnic groups that prefer pork either raw, partially cooked, or lightly processed. Moreover, most habitants in Central and Northwestern China don't eat raw pork. More and more habitants ate scalded cubes of pork and mutton in winter. If the cube of meat was too large and the time of scald was insufficient, the temperature in the pork center would not be sufficient to kill the larvae. The high incidence season of trichinellosis is in winter from December to February; it is believed to be the result of eating scalded meat or dumpling during the winter (Wang et al., 1998).

Outbreaks of trichinellosis associated with wild game meat occurred mainly in southwestern China. The first outbreak caused by eating game (raw bear meat) occurred in Sichuan province in December 1968. Another outbreak caused by raw bear meat, with 58 cases and one death, occurred in Sichuna in 1972 (Wang \& Luo, 1981). Six outbreaks associated with game meat have occurred in Yunnan during 1964-1999: three outbreaks caused by eating wild boar meat, two by muntjak meat, one by bamboo rat meat (Yang, 1991). Trichinellosis resulting from the ingestion of air-dried bear meat has also occurred in Xizang (Ling, 1998). In the 1960 s, $47.1 \%$ (49/104) of wild foxes in Gansu and $7.7 \%(1 / 13)$ of wild bears in Heilongjiang were infected with T. spiralis. Lion and raccoon dog were found to be infected with Trichinella. Wildlife population has been on the increasing in the recent years since wild animals are protected by the law and hunting them is prohibited in China. Although the prevalence of trichinellosis among wildlife in China is not still unknown, the wild animals appears to be most likely the another important reservoir of the trichinellosis foci in the forest and woodland. Recently, owing to the illegal hunting in China, some wildlife was killed by poachers. It is quite natural that the poached animals are not examined for Trichinella and such meat will become another source of infection. The natural infection of goat with T. spiralis was confirmed in Yunnan (Yang, 1991). The natural infection rate of cattle was from $0.14 \%$ to
$0.72 \%$ in Nanyang area of Henan when the animals were slaughtered and examined by direct microscopic observation (Wu, 1986). The above facts emphasize the increasing significance of herbivorous and wild animals as source for human trichinellosis. Hence, in addition to the inspection of pork, meat of herbivorous and wild animals should also be under quarantine for the efficient control of trichinellosis in China.

\section{REFERENCES}

BAI W.H. Report of two human cases with trichinellosis. Yunnan Medical Journal, 1965, 7, 42.

Chang J., ZhaO Q.F., Li Y., Li G.L., Chen J.S. \& Liu D. Human infection with Trichinella spiralis in Nanyan region of Henan province. Chinese Journal of Parasitology E Parasitic Diseases, 1991, 9 (suppl), 142-143.

Cui J., WANG Z.Q., ZHU W. \& ZHANG R.G. Seroepidemiological study of Trichinella spiralis infection in central China. Helminthologia, 1999, 36, 235-239.

Fu D.R., Qian D.Z., Han X.Q., PAN G.X. \& Zhang Z. Seroepidemiological survey of human trichinellosis in Ningxia. Chinese Journal of Parasitology \& Parasitic Diseases, 1991, 9 (suppl), 96-98.

Gan Y.C., Chen Z.Q., Yang L., Yu X.G., Nong L.H., Nong G.Q., TANG Z.Y. \& Lu J.Z. Epidemiological survey of trichinellosis in Baizhan village of Debao county of Guangxi. Guangxi Preventive Medicine, 1995, 1, 163165.

Gou W.M., Yu D.J., Langga Z.M., Gou C.M., Chan Z., Jia J., Cien D.L., DA D., Jing Y.H. \& BianBa Z.M. Distribution of human parasites in four counties of Linzhi prefecture, Lhasa, Xizang. Chinese Journal of Parasitology \& Parasitic Diseases, 1991, 9 (suppl), 107-109.

HaO C.L, Si H.Z., Yuan T.P, Fan X.T., Wang B. \& Zheng Y.M. The first report of trichinellosis in Shangxi Aluminum Factory. Practical Journal of Medical Technology, 1997, 4, 421-422.

Huang F.C. Report of one case of human trichinellosis. Chinese Journal of Internal Medicine, 1965, 13, 392.

Jiang H.F., Bai Y.T., Wang J.W., Meng Y.L., GaO F.L., Yu J.S. \& YANG X.W. Report of 9 cases of trichinellosis caused by eating dog meat. Journal of Postgraduates of Medicine, 1989, 9, 9.

Li N.F., Xu B.L., Zhang Y.L. \& CHANG J. Epidemiologic survey of trichinellosis population of Luohe city. in: Trichinellosis. Ortega-Pierres G., Gamble H.R., Knapen F. van \& Wakelin D. (eds). Centro de Investigacion y Estudios Avanzados del Instituto Politecnico Nacional, Mexico, D.F. Mexico, 1996, 499-501.

Li S.T., Wang X.Z., Qiu Z.L., Wei J.B. \& Zhang X.F. Development and application of rapid ELISA kit for diagnosis of zoonotic trichinosis. Chinese Journal of Zoonoses, 1991, 7, 23-25.

LING Y.L. A case of trichinellosis caused by eating air-dried bear meat. Tibetan Journal of Medicine, 1998, 20, 54. 
LiU H.B., Li Y.B., Ge F.T., Li B.J., SAn L.J. \& Hou F.L. Preliminary investigation on the distribution of human tissue parasites in Hebei province. Medical Animal Control, 1994, 10, 148-150.

Lu H.X., Huang W.H., Yao Q.Y., Che G., Ma W. \& Deng T.X. An outbreak of trichinellosis resulting from consumption of raw salted pork. Chinese Journal of Zoonoses, 1996, 12, 54-55.

MA J.H., GUO H.Q. \& YANG H.M. Surveillance and analysis of different groups of human infected with Trichinella spiralis in Nantong city. Chinese Journal of Parasitic Disease Control, 1997, 10, 72.

PANG T.X. Investigation of outbreak of trichinellosis resulted from the consumption of instant-boiled mutton. People's Military Surgeon, 1991, 10, 14

PANG Y.K. \& ZHANG L.L. Data analysis of human trichinellosis epidemic in Yunnan province from 1964 to 1997. Chinese Journal of Parasitology \& Parasitic Diseases, 1999, 17, 58-59.

Pun K.K., Wong W.T. \& Wong P.H.C. The first outbreak of trichinosis in Hongkong Chinese. American Journal of Tropical Medicine E Hygiene, 1983, 32, 772-775.

WANG B.K. \& LuO X.P. Report of 58 cases with trichinellosis caused by eating bear meat. Chineses Journal of Preventive Medicine, 1981, 15, 143-144.

WANG C.K. Survey of human infection with Trichinella spiralis and with cysticercus in Pengxi county. Chinese Journal of Epidemiology, 1993, 14, 312.

Wang P.S., Geng G.Y., Lai Z.M., Zhang J.S. \& Yu E.D. An outbreak of trichinellosis caused by eating dog meat. Chinese Journal of Epidemiology, 1989, 10, 69.

WANG Z.Q., CUI J., WU F. \& JIN X.X. Seven outbreaks of trichinellosis in China during 1992-1996. Journal of Egyptian Society of Parasitology, 1997, 27, 529-538.

WANG Z.Q., CuI J., Wu F, MaO F.R. \& Jin X.X. Epidemiological, clinical and serological studies on trichinellosis in Henan province, China. Acta Tropical, 1998b, 71, 255268.

Wu A.H., CaI C.H. \& Yuan Y.X. An investigation of trichinellosis in Denxian county, Henan province. Journal of Parasitology \& Parasitic Diseases, 1986, 4, 66.

Wu Z.X., Dong J.M. \& YE J.J. Analysis of the epidemiological situation of human trichinellosis in Hubei province. Chinese Journal of Parasitic Disease Control, 1996, 9, 310311.

XU E.Y. \& MU Y.N. Investigation of trichinellosis caused by eating instant-boiled mutton. Journal of Epidemiology, 1981, 2, 103-104.

Xu J.T., Sun T., Ge L.M., Chen X.Q., Wang H. \& DiaO E.R. Serological investigation of Trichinella infection in rural areas of Lioning province. Chinese Public Health, 1992, 8, 252.

YANG H.M. Studies on epidemiology and control of trichinellosis in Yunnan province. Chinese Journal of Parasitology \& Parasitic Diseases, 1991, 9 (suppl), 79-82.
Ye J.J., Zhang S.Q., Chen S.L., Sheng X.D. \& Pei S.J. Investigation on infection of the human Trichinella spiralis in Hubei province. Chinese Journal of Parasitic Disease Control, 1998, 11, 111-113.

ZuO D.P. Report of 34 cases of trichinellosis in Xizang. Journal of Beijing Second Medical College, 1982, 47-48. 